\title{
New Thoughts on the Construction of College Online Teaching Platform Adapting to a Large Concurrent Access
}

\author{
Xiaohua Xiao, Guili Zhang, Heping Pu \\ Network and Information Center, Southwest Petroleum University, Chengdu, China \\ Email: xiaoxh@swpu.edu.cn,15995648@qq.com,puheping@swpu.edu.cn
}

How to cite this paper: Xiao, X. H., Zhang, G. L., \& Pu, H. P. (2021). New Thoughts on the Construction of College Online Teaching Platform Adapting to a Large Concurrent Access. Creative Education, 12, 1047-1056.

https://doi.org/10.4236/ce.2021.125077

Received: April 14, 2021

Accepted: May 21, 2021

Published: May 24, 2021

Copyright ( 2021 by author(s) and Scientific Research Publishing Inc. This work is licensed under the Creative Commons Attribution-NonCommercial International License (CC BY-NC 4.0).

http://creativecommons.org/licenses/by-nc/4.0/

\begin{abstract}
The 2.0 action plan of educational informatization has put forward the goal of "three whole, two high and one big". The online teaching platform of colleges and universities is one of the important contents of "Internet plus education platform". It is an urgent requirement for the information construction of colleges and universities to build an online teaching platform to adapt to large concurrent access. There are advantages and disadvantages in the four online teaching platform construction modes of self-study, introduction, local and cloud. Compared with the construction of online teaching platform in Colleges and universities in the new situation, there are some new problems. Large concurrent access puts forward new requirements for platform performance, network bandwidth, teachers and students' literacy, etc. Based on the new goal of educational informatization 2.0 and the existing main problems, this paper puts forward countermeasures and suggestions from the aspects of new goal of platform construction, new concept of platform selection, new mode of platform deployment, new way of network unblocking, new method of teaching evaluation, new requirements of quality improvement, etc.
\end{abstract}

\section{Keywords}

Online Teaching, Informatization, Platform Construction, Concurrency, College Education, Digital Campus, New Thinking, College Construction

\section{Introduction}

COVID-19 2020 will have a huge impact on all walks of life, and higher education is no exception. Following the principle of "No postponement of teaching, no suspension of classes" (Ministry of Education, 2020:

http://www.moe.gov.cn/jyb_xwfb/gzdt_gzdt/s5987/202001/t20200129_416993.ht 
ml) All teachers and students are in a hurry to "respond to the challenge". In a short time, the necessity and urgency of online education have been placed at the "highest level", and online education and teaching have become the focus topic of the whole society (Xie, Qiu, Huang, \& Wang, 2020). At the beginning of the course, there were various problems and challenges (Yang et al., 2020), and various emergencies kept happening, both in terms of the platform and at the individual level of teachers and students. For online teaching, there are both thumb up and ridicule on the network. As a member who has been engaged in the construction of online teaching platform in colleges and universities for a long time, through these phenomena, I should sort out the existing problems and causes of online teaching platform in time, and reflect deeply on the construction of online teaching platform in accordance with the new situation, which will definitely play a positive role in promoting the construction of online teaching platform.

\section{Status of Online Teaching Platform Construction in Universities}

Internet online teaching has entered the 4.0 era, which mean the new stage of wisdom teaching of "Internett" classroom (Sun, 2016). As one of the core contents of digital campus construction, online teaching platform, after years of development, has become a necessary platform for school teaching reform and a booster for improving the quality of talent cultivation, and is playing an increasingly significant role in the process of school education and teaching.

Although the constructional path of online teaching platforms in colleges and universities are different and the results are various (Lin, Huo, \& Wang, 2016), generally speaking, they can be roughly divided into four types: the first is the self-research platform of the university. The online teaching platform which adopts this mode has the advantages of close combination with the needs of their school and easy updating and upgrading, while the disadvantages are high requirements on the technical level of personnel and relatively long development cycle. The second is to deploy the purchased commercial platform on campus. The universities that adopt this kind of model account for relatively large. The advantages of this mode are short deployment time, quick results, and relatively low technical requirements for personnel development. Its disadvantage is that it is more troublesome to meet the customization of the school's characteristic applications. Each upgrade affects the customization function, and the upgrade cost is high. The third is to purchase and use mature cloud platforms. This mode still has the disadvantage that it is difficult to meet the characteristics of the application, but its advantages are also very prominent, reducing the system and security maintenance of the software and hardware platform in colleges and universities, and reducing the pressure of one-time high purchase cost by annual payment. The fourth is construction of a diversified online education platform. This approach gives each teaching unit more autonomy to choose, but from the perspective of students, it is also inconvenient to use multiple platforms (Figure $1)$. 


\section{Analysis of the New Problems Existing in the Construction of Online Teaching Platform in Colleges and Universities under the New Situation and Their Causes}

In the education information 2.0 action plan, the development goal of "three complete, two high and one large" is proposed by 2022 (Ministry of Education, 2018: http://www.moe.gov.cn/srcsite/A16/s3342/201804/t20180425_334188.html), and the online teaching platform is an important content and carrier to realize this development goal. Facing the new situation, all colleges and universities are actively accelerating the pace of the construction of online teaching platform, which also exposes many new problems, which are mainly reflected in the platform selection, deployment, supporting environment, teaching evaluation, teachers and students' quality and so on.

\subsection{Difficult Choice of Many Platforms}

A good online teaching platform should not only adapt to various teaching scenarios, but also meet the needs of teaching management, resource construction and other aspects. It also involves many factors such as teachers' and students' teaching evaluation. In the actual work, the choice is difficult mainly in: one is the function choice. Some platforms have complete functions, but few application cases; some platforms are widely used, but some personalized functions are lacking. Second, deployment. The information security risk of on-campus deployment is relatively small, but the supporting platform has a large investment and large maintenance. Cloud deployment not only imposes great pressure on the outlet of campus network, but also becomes a prominent problem of information

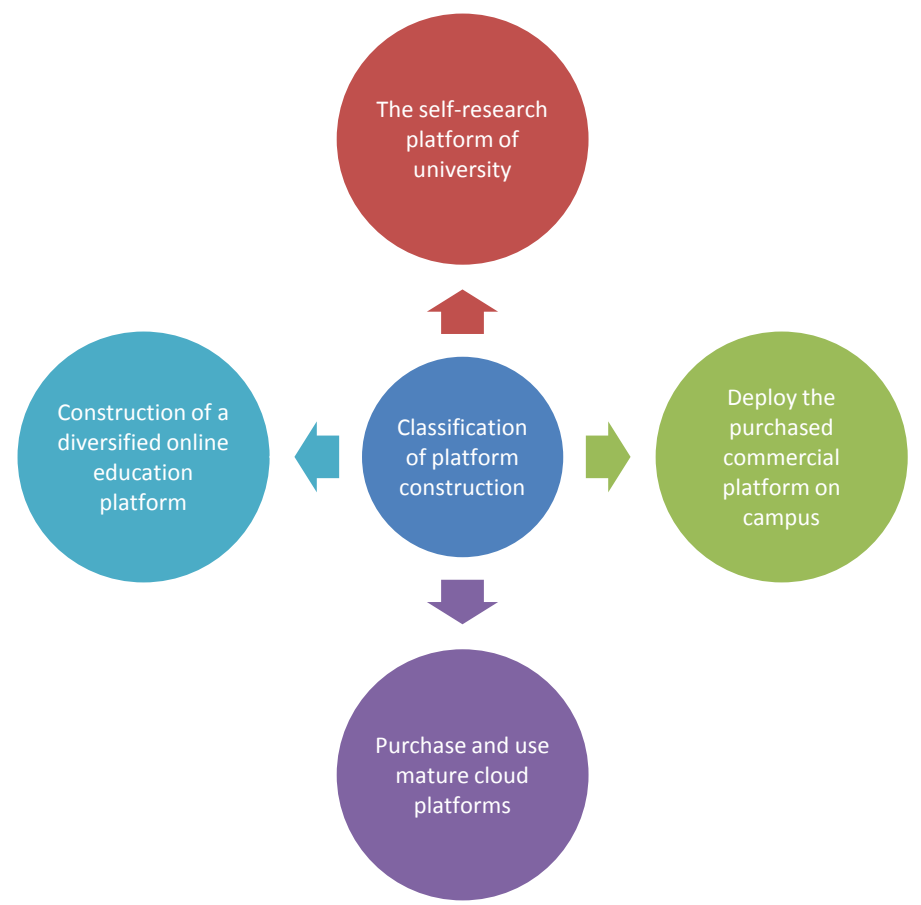

Figure 1. Classification of platform construction design. 
security. Third, capital investment. No matter which way is adopted to build online teaching platform, the total investment is not small. On the one hand, schools hope that the platform has complete functions and excellent performance, but on the other hand, they hope that the one-time investment is less and the total investment is low. It is difficult to balance the two in practical operation (Figure 2).

\subsection{The On-Campus Support Platform Cannot Meet the Needs of Large Concurrent Use}

Both the Education Informatization 2.0 Action Plan and the "40 Rules for Higher Education" have put forward defined requirements for the informatization of teaching. The deep integration of informatization and school education and teaching is not only the nature of reform pilot, but also the problem of large-scale promotion and application. The COVID-19 epidemic in 2020 accelerated this process, and colleges and universities across the country had to start a full-staff online teaching mode. The long-term auxiliary role of online teaching has been reversed in this stage. Although the teaching effect has yet to be tested in practice, the large concurrent requirements have become an indiscontestable fact. According to author, support platform performance of the campus is limited, expansion in a short period of time is difficult, in addition to a few colleges and universities, the vast majority of colleges and universities are not using the deployment of online teaching platform in the school, but chose a variety of teaching platform with the clouds, this fully shows that the campus support platform is difficult to meet the needs of the large concurrent use between teachers and students.

\subsection{The Outlet Bandwidth of Campus Network Greatly Affects the Development of Concurrent Online Teaching}

In the beginning of the online teaching platform construction, the most colleges and universities are teaching platform deployed inside the school, one of the reasons is when the cloud platform also very little, or not enough maturity, and

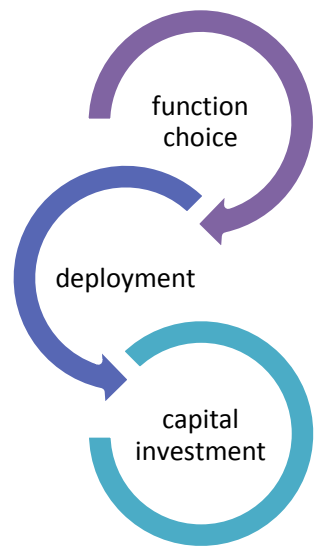

Figure 2. Considerations for platform selection. 
certainly some of the important factors mentioned before, the campus network export bandwidth was smaller and it is difficult to achieve the smooth access of video resources. At the same time, the difficult control of security is also a more tangled problem for schools. In recent years, the campus network bandwidth has been increasing, though which was supposed to be able to meet the increasing demand of off-campus access traffic caused by the increase of the majority of teachers and students' smart phones. However, new changes have taken place in the actual situation. Tens of thousands of people gather in the classroom to access the teaching platform at the same time. It is technically difficult to rely solely on mobile phone traffic, and it is more likely to be solved by deploying high-density Wi-Fi in the classroom. If the online platform is deployed in the cloud, higher requirements are put forward for the outlet bandwidth of the campus network. If the online platform is still on campus, the campus network exit is also a chock point when confronted with off-campus visit-based scenarios. Therefore, whether it is deployed on campus or off campus, the outlet bandwidth of campus network may become an important link affecting the development of online teaching when it is used on a large scale in different scenarios.

\subsection{Evaluation Data of Large Concurrent Teaching Applications Need to Be Integrated Urgently}

Generally, there is a mainstream public online teaching platform for tall the teachers and students to use, but also there are many scattered specialized teaching platform, such as experimental teaching platform, virtual simulation platform and training platform, foreign language teaching platform and so on, each platform is the carrier of teaching and learning between teachers and students, all of them is an important part of evaluating teachers' teaching and students' learning situation. In this sense, only by summarizing and analyzing the data of all platforms involved by teachers and students can a credible evaluation conclusion be drawn. At present, some platforms do not have evaluation function, and the data of each platform are independent of each other. Even those platforms with evaluation modules are self-contained. Meanwhile, large concurrent teaching applications have led to a large increase in evaluation data, which is in urgent need of integration.

\subsection{The Information Literacy of Some Teachers and Students Is Not Suitable for the Application of Large Concurrent Teaching}

Information literacy is the comprehensive performance of information application in real life (Yang \& Hu, 2019). The revolution of classroom teaching in school and the reversal of the mode of whole-course online teaching all put forward corresponding requirements for the information literacy of teachers and students. Teachers and students must have certain information literacy in order to achieve the expected teaching effect. Part of the old teachers because of the age of the information operation skills are not skilled, although they want to use the information means in the heart, but the heart is willing but the strength is 
insufficient, it is difficult to achieve the application of information means calmly in teaching. Some young teachers, although proficient in operation, do not have enough grasp of the teaching rules under the information conditions. They may fall into the situation of application for application, and the effect may not be ideal. Some students' understanding of informationize teaching is not in place, and the function of the platform is not clear. Some students are not skilled in operation skills, and lack the internal motivation to take the initiative to use informationizes means to learn.

\section{New Thinking on the Construction of Online Teaching Platform in Colleges and Universities under the Requirements of New Goals}

In the face of these new problems of online teaching platform under the new situation, we can only take the new goals proposed by education informatization 2.0 as the guidance, change traditional thinking habits, solve development problems through cloud computing, big data and other emerging technologies, and promote the construction of large concurrent application online teaching platform in multiple ways and methods.

\subsection{New Targets for Platform Construction}

In the new era, the new goal, for complying with the requirements of the education informationization 2.0 action plan (Ren, 2018), and timely adjusting the construction goal of the online teaching platform of colleges and universities, new targets for online teaching platform construction: online teaching platform construction will be an important part of the university's "Internet + Education Platform", an important carrier to deepen education and teaching reform and improve the quality of talent cultivation, and a strong support to lead the teaching modernization and realize the high-quality development of the school.

\subsection{New Concepts for Platform Selection}

The main reason for the difficulty of choosing a platform is that you want to achieve all your goals on one platform. Since it is almost impossible to achieve in practice, we may as well change our thinking and use new ideas to make it easier. One is the coexistence of multiple platforms. Don't hope for a platform to solve all problems, many special platforms have their distinguishing feature (Li, Chen, Li et al., 2018; Huang \& Li, 2016), integration of the difficulty is very big, for example it's difficult to do the virtual simulation platform and the center of teaching platform, engineer training platform and train platform, foreign language teaching to through a platform to realize these functions. In addition to technical problems, the company itself is also struggling to keep up. Second, professional platform do professional things. It is not difficult to find that similar platforms have their own advantages and disadvantages, but different types of platforms have difference on their focus points at work. First of all, we must 
choose the platform belonging to this professional category according to the purpose of use, and then choose the preferred platform in the same professional category. Third, the balance between application and safety. There is no absolute safety system. Comprehensive implementation of safety measures, congestion combined and timely handling found safety risks is a long-term solution. Through online backup, semi-offline backup, offline backup and other modes, the cloud platform teaching resources and all kinds of course resources are backed up to ensure data security (Dong, 2019). Reduce the choice between the cloud platform and the local platform, and the more mature platform with fewer security incidents in the cloud platform can also be used (Figure 3).

\subsection{New Platform Deployment Mode}

With the development of informatization, people's understanding of the local deployment and cloud deployment of online teaching platform is no longer an either-or concept. In fact, the local deployment and cloud deployment of online teaching platform can also be mutually complementary and organically unified to establish a good ecological environment for online platform education ( $\mathrm{Zhu}$, Gong, \& Yang, 2016). Based on the accumulation of practice and the development of technology, the author believes that local and cloud deployment methods can be adopted at the same time according to different uses, and the respective advantages of the two methods can be given full play to, so as to not only meet the needs of on-site teaching on campus, but also quickly respond to the needs of large-scale off-campus online teaching. For example, we will mainly take the off-campus access online boutique open course platform deployment in the cloud, and take the school daily teaching support center platform deployed in the campus, which already so effectively avoids the huge impact to the campus network export bandwidth and can guarantee the high-quality goods open courses platform of high concurrent access. Meanwhile, when it requires a large online teaching, relying on the existing cloud platform, we can quickly complete course platform transference and content construction, which is similar to big

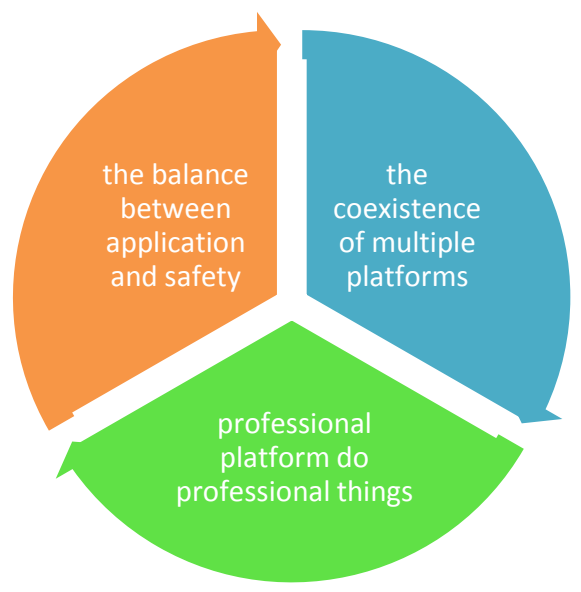

Figure 3. The ternary concept of platform selection. 
and power generation business platform, online teaching platform of cloud takes a cluster system, load balance architecture, and optimizes design of the WEB front-end, daemon, database, server, etc. Good scalability of the platform provides strong software and hardware support for online teaching (Huang, $\mathrm{Xu}, \&$ $\mathrm{Qu}, 2019)$.

\subsection{New Channels for Unimpeded Network}

The smooth network can be divided into two situations: the online teaching platform in off-campus and on-campus, which needs to be taken targeted measures and to be solved in a multi-way. In the school regular network deployment at the same time, it can also focus on the two aspects of the operators to solve the problem of unblocked network. First, it is necessary to coordinate well the interconnection between the operator's export regional network and the campus network, so as to reduce the pressure on the campus network caused by the students detour to visit the local teaching platform. Second, coordinate with operators to fully cover $5 \mathrm{G}(4 \mathrm{G})$ network on campus, drain the traffic of operators, and reduce the exit pressure on campus network brought by students accessing cloud platform through campus network. Third, jointly build and share campus network with operators to solve the problem of bandwidth access to online teaching platform within and outside campus.

\subsection{New Methods of Teaching Evaluation}

On the one hand, informationize teaching can provide more data reference for teaching evaluation, especially the retention of process data, and it provide data support for the adoption of new methods in formative evaluation, process evaluation and result evaluation. On the other hand, teaching evaluation is a complex systems engineering, which needs to be evaluated in all directions, multidimensional and three-dimensional. When we rely on the online teaching platform for teaching evaluation, we suggest some new methods to make the evaluation result more realistic. One is to expand data sources for evaluation. In addition to integrating data from multiple teaching platforms, we should also collect some conventional evaluation data in an all-round and multi-dimensional way as far as possible. The second is to use new technologies such as big data analysis. It is difficult to process and analyze massive teaching process data through conventional methods, so we should introduce big data processing technology to process the collected teaching data, find out the factors with greater value, improve and optimize the evaluation indexes of teachers' teaching and students' learning, so as to improve the evaluation accuracy.

\subsection{New Requirements for Improving Literacy}

The improvement of information literacy of teachers and students is not only the explicit requirement of the education informatization 2.0 action plan, but also the necessary condition to improve the application level of teaching infor- 
matization. It is the basic requirement for qualified teachers in the new era to have the corresponding information literacy and carry out information teaching skillfully. It is the premise for students to achieve the expected effect of information teaching to have a certain information learning ability. Neither of the two is indispensable. On the one hand, students can be equipped with basic information learning ability in a short period of time through the reasonable development of teaching plans, and students can be trained with high-level information literacy in the long-term teaching process through the deep integration of information technology and courses. On the other hand, we should strengthen special operational training on teachers' use of online platforms and classroom interactive software, so that they can carry out informationize teaching as soon as possible. Meanwhile, we should strengthen the training of teachers' teaching methods and methods through observation, seminars, reports and other forms, so as to continuously improve the teaching level of teachers under the condition of informationization. Through the multiple innovation of information literacy education model (Wang \& Wu, 2018), the quality of talent training can be improved while improving the information literacy of teachers and students.

The effective integration of online courses and university teaching has become one of the main forms of education modernization in the future (Tong, 2019). The importance of large concurrent online teaching platform construction is self-evident, the construction of an online platform to the satisfaction of teachers, students and staff is the goal of information workers to pursue, in the face of the new situation to take the initiative to carry out some new thinking is very necessary. But in the actual construction, because of the difference of every school's situation, we must combine the actual school, make the best of the situation, go with the wind, in order to achieve twice the result with half the work.

\section{Acknowledgements}

This paper is the research achievement of the key research topic of teaching reform of Southwest Petroleum University in 2018, "research and practice of education big data information teaching reform based on ubiquitous learning environment” (Project No. X2018JGZDI050).

\section{Conflicts of Interest}

The authors declare no conflicts of interest regarding the publication of this paper.

\section{References}

Dong, X. F. (2019). Optimizing University Teaching Platform to Serve Teachers and Students in Teaching and Learning. Experimental Technology and Management, 36, 216-220.

Huang, H. L., \& Li, Y. (2016). Research on the Construction of Maker Space of Engineering Training Platform. Experimental Technology and Management, 33, 156-159.

Huang, Z. L., Xu, L. S., \& Qu, S. C. (2019). Design and Optimization of High Concurren- 
cy Web E-Commerce System. Computer and Digital Engineering, 47, 1719-1724+1775.

Li, L., Chen, Y. F., Li, Z. J. et al. (2018). Construction and Practice of Large-Scale Online Virtual Experiment Teaching Platform. Experiment Technology and Management, 35, 144-147.

Lin, M. D., Huo, X. G., \& Wang, Y. F. (2016). Comparative Analysis of Domestic MOOC Platform Based on User Perspective. China Adult Education, No. 8, 71-77.

Ministry of Education (2018). Notice of the Ministry of Education on Printing and Distributing the Action Plan of Educational Informatization 2.0. http://www.moe.gov.cn/srcsite/A16/s3342/201804/t20180425_334188.html

Ministry of Education (2020). How Do Children "Stay at Home" to Learn after the Postponement of School? Ministry of Education: Using the Internet Platform. Despite the Suspension of Classes, but Continue to Learn. http://www.moe.gov.cn/jyb_xwfb/gzdt_gzdt/s5987/202001/t20200129_416993.html

Ren, Y. Q. (2018). China's Education Informatization in the New Era-Interpretation of the Education Informatization 2.0 Action Plan. Audio Visual Education Research, 39, 27-28+60.

Sun, S. H. (2016). Online Teaching 4.0: “Internet+" Classroom Teaching. China Education Informatization, No. 14, 17-20.

Tong, J. (2019). On the Development and Application of the Integration of Online Courses and College Teaching-Comment on "Large Scale Opening: How MOOC Changed the World". Chinese Science and Technology Paper, 14, 1062.

Wang, Y., \& Wu, J. (2018). The Evolution and Innovation of Information Literacy Education in the New Era-A Summary of 2018 National Symposium on Information Literacy Education in Colleges and Universities. Journal of University Library, 36, 21-27.

Xie, Y. R., Qiu, Y., Huang, Y. L., \& Wang, Q. L. (2020). Characteristics, Problems and Innovation of Online Teaching Mode of "No Suspension of Classes" during Epidemic Prevention and Control. Research on Electronic Education, No. 3, 20-28.

Yang, J. Y. et al. (2020). Online Teaching Practice and Experience during the Epidemic. China Audio Visual Education, No. 4, 29.

Yang, Y., \& Hu, Z. F. (2019). The Current Situation and Promotion Strategy of Information Literacy of University Teachers in the Era of Internet Plus. China Audio Visual Education, No. 4, 117-122.

Zhu, W. W., Gong, X. H., \& Yang, J. S. (2016). Research on University Service Orientation in MOOC Platform Education Ecological Environment. Adult Education, 36, 1-5. 